\title{
Pneumocephalus following Lumbar Spine Surgery: A Rare Cause of Delayed Emergence from Anesthesia
}

\author{
Ritesh Lamsal $^{1} \quad$ Rajeeb K. Mishra ${ }^{1} \quad$ Niraj Kumar $^{1}$ \\ ${ }^{1}$ Department of Neuroanesthesiology and Critical Care, All India \\ Institute of Medical Sciences, New Delhi, India
}

\begin{abstract}
Address for correspondence Niraj Kumar, MD, Department of Neuroanesthesiology and Critical Care, Room No. 709, Neuroscience Centre, All India Institute of Medical Sciences, New Delhi 110 029, India (e-mail: drnirajaiims@gmail.com).
\end{abstract}

J Neuroanaesthesiol Crit Care 2018;5:30-32.

\begin{abstract}
Keywords

- delayed emergence

- lumbar spine

- pneumocephalus

Pneumocephalus is an unusual presentation after lumbar spine surgery. We report the case of a young healthy patient, who had delayed emergence from anesthesia after undergoing an uncomplicated lumbar spine surgery. After shifting to the Intensive Care Unit, the patient had an episode of generalized tonic-clonic seizure. Computed tomography scan revealed the presence of pneumocephalus. The patient was managed conservatively, extubated the following day and discharged with no neurological deficits.
\end{abstract}

\section{Introduction}

Delayed recovery from anesthesia always poses a diagnostic challenge for the anesthesiologist because multiple factors need to be considered. This is particularly true in short surgeries using newer anesthetic agents where delayed recovery is not anticipated. Some of its causes are easy to identify and temporary, whereas others may have serious long-term effects.

Lumbar spine surgeries are routinely performed in most neurosurgical set-ups around the world, and most of these patients are extubated in the operating room. Pneumocephalus has a high incidence after craniotomies and cervical spine surgeries, but its occurrence is rare in uncomplicated lumbar spine surgeries. ${ }^{1,2}$

\section{Case Report}

A 2-year-old male child, weighing $10 \mathrm{~kg}$, with no known co-morbid illness was scheduled to undergo lumbar laminectomy (L2-L3) and excision of an intramedullary spinal cord tumor. The child was brought by the parents to the hospital with a brief history of difficulty in walking. Preoperative evaluation was unremarkable, and all laboratory parameters were within normal limits.

Anesthesia was induced with fentanyl $20 \mu \mathrm{g}$ and propofol $20 \mathrm{mg}$. Tracheal intubation was facilitated with rocuronium $10 \mathrm{mg}$, and a standard-sized micro-cuffed endotracheal tube was inserted. Intraoperative monitoring was done with pulse oximetry, noninvasive blood pressure, electrocardiogram, nasopharyngeal temperature, end-tidal gases and $\mathrm{CO}_{2}$. Forced warm-air blanket was used to maintain normothermia. Anesthesia was maintained with oxygen with nitrous oxide (40:60), sevoflurane (1\%-1.5\%) and boluses of rocuronium and fentanyl as required. After laminectomy and tumor excision, the dura was repaired and its adequacy was confirmed by valsalva manoeuvre. The total duration of surgery was $3 \mathrm{~h}$. At the end of the surgery, the child did not regain consciousness even after $1 \mathrm{~h}$ of discontinuing sevoflurane and adequate neuromuscular reversal. Hemodynamic parameters, as well as body temperature were normal. The pupils were bilaterally constricted, equal and reacting to light; ventilatory efforts were adequate. The child was not extubated and shifted to the Intensive Care Unit (ICU) for further investigations. Immediately after reaching the ICU, the child had a sudden episode of generalized tonic-clonic seizure lasting for around $10 \mathrm{~s}$ with spontaneous cessation. Loading dose of $150 \mathrm{mg}$ $(15 \mathrm{mg} / \mathrm{kg})$ phenytoin was administered to the patient. Postseizure investigations including arterial blood gases, serum electrolytes and glucose were normal. A computed tomography (CT) scan revealed the presence of pneumocephalus in the pre-pontine cistern (-Fig. 1). The patient had full recovery of consciousness and followed commands after $3 \mathrm{~h}$ in the ICU. The trachea was extubated $12 \mathrm{~h}$ later. Further course in the ICU was uneventful, and he was discharged from the ward on the seventh postoperative day without any neurological deficit.
Dol https://doi.org/ 10.1055/s-0037-1616038. ISSN 2348-0548.
Copyright $\odot 2018$ Indian Society of Neuroanaesthesiology and Critical Care
License terms

()(1) $\Theta \circledast$ 


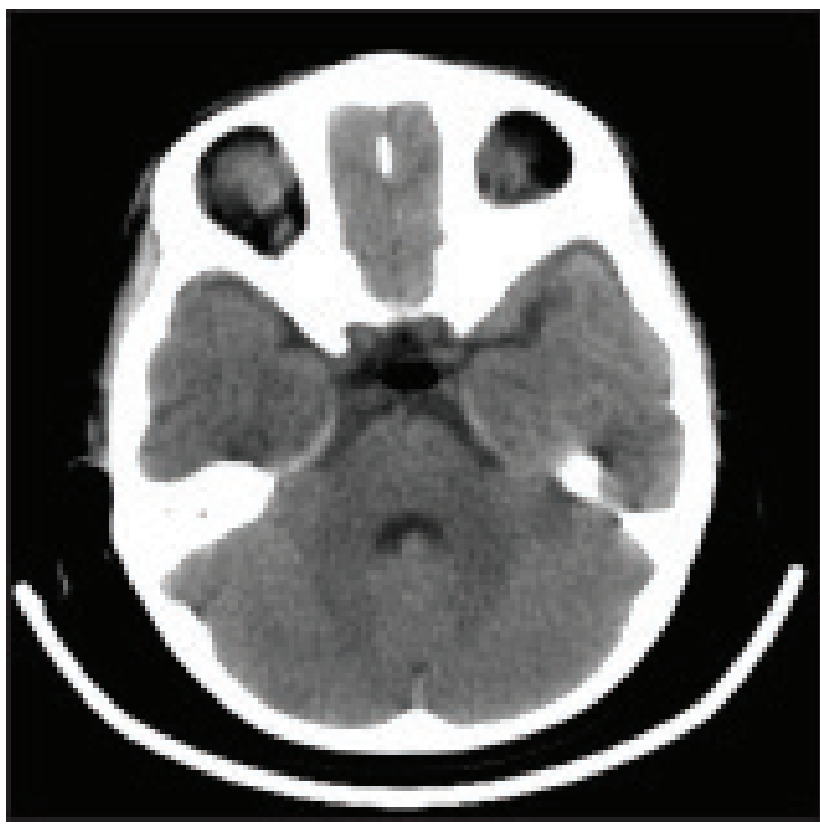

Fig. 1 A noncontrast computed tomography scan showing pneumocephalus in the prepontine cistern.

\section{Discussion}

Delayed emergence from anesthesia is multifactorial and warrants close attention. The most common cause of delayed emergence from anesthesia is pharmacological - drugs that are used in the perioperative period - their overdose, interactions or residual effects. Other common causes include hypothermia, electrolyte disturbances, hypercarbia, acidosis, hypoglycemia, obesity and advanced age. In most instances, the etiology is readily identifiable and is promptly reversible. More serious and unexpected causes after general anesthesia include cerebral hypoxia, seizure, central anticholinergic syndrome, cerebral hemorrhage, embolism or thrombosis. Pneumocephalus is a rare cause that is not encountered too often outside neurosurgical operating rooms. Pneumocephalus is formed once cerebrospinal fluid flows out of a surgical or traumatic defect in the dura and air takes its place to equilibrate the pressure differential.

The incidence of pneumocephalus is extremely high following craniotomies. Most of these cases are benign and resolve spontaneously. Sometimes, it may manifest as tension pneumocephalus with severe headache, altered sensorium, seizure or focal neurological deficit. In our patient, pneumocephalus close to the prepontine cistern manifested in generalised tonic-clonic seizure. Although the exact mechanism of seizure in this case is difficult to ascertain, possible causes include sudden rise in intracranial pressure, alteration in cerebrovascular fluid homoeostasis and change in neuronal membrane excitability because of the air pocket. Pneumocephalus has been reported after traumatic injuries, spinal anesthesia and accidental dural puncture whilst performing epidural analgesia and epidural steroid injections. ${ }^{3-7}$ However, there are only a few case reports that describe it after lumbar spine surgery. Akyüz et al described a case of delayed pneumocephalus and pneumorrhachis 2 months after lumbar spinal fusion surgery secondary to infection. ${ }^{6}$ Karavelioglu et al reported a case of pneumocephalus after lumbar disc surgery with pedicle screw fixation, where they postulated that they may have inadvertently torn open the arachnoid layer while trying to retrieve a large disc fragment. ${ }^{7}$ In another case, diffuse pneumocephalus after posterior lumbar surgery for spinal stenosis was seen, where dural tear was noted intraoperatively and repaired. ${ }^{8}$ Turgut and Akyüz reported a case of symptomatic tension pneumocephalus after a repeat surgery for L5 to S1 discectomy. ${ }^{9}$ Pirris and Nottmeier reported pneumocephalus after lumbar arthrodesis, which they attributed to intraoperative reverse Trendelenburg position with an unintended durotomy. ${ }^{10}$

The use of nitrous oxide has been implicated in the enlargement of pneumocephalus. Nitrous oxide dissolves into the bloodstream and enters closed spaces at a rate faster than the rate of absorption of nitrogen present in that space. Even though nitrous oxide use is contraindicated if pneumocephalus is already present, there is no strong evidence to discontinue its use in usual neurosurgical procedures. Nitrous oxide was used in this case and may have been contributory.

Continuous positive airway pressure ventilation has also been implicated in the development of pneumocephalus by increasing positive pressure in the upper airway and causing a slow entry of air into the intracranial space. Similarly, coughing, sneezing, Valsalva, forceful blowing and even positive pressure during bag-mask ventilation can enlarge the size of pneumocephalus.

The treatment of pneumocephalus is mostly supportive with gradual resorption of the air over several days. However, tension pneumocephalus, caused by large volume of air, can result in sudden mass effect with major neurological sequelae. It is a neurosurgical emergency that needs to be promptly diagnosed and decompressed with interventions such as craniotomy, burr role evacuation, needle aspiration or ventriculostomy placement. $\mathrm{High} \mathrm{FiO}_{2}$ may be helpful in treating pneumocephalus. ${ }^{11,12}$ When high concentration of oxygen is used, it reduces blood and brain nitrogen concentrations, increasing the nitrogen concentration gradient across the pneumocephalus-containing cavity, promoting its absorption.

To conclude, pneumocephalus is a rare presentation after uncomplicated lumbar spine surgery and may not be suspected by many anesthesiologists. Pneumocephalus should be a differential diagnosis following any spinal surgery when unanticipated complications such as delayed recovery from anesthesia, failure of extubation and neurological manifestations are present that is not explained by any other usual cause. A head CT-scan is warranted in such cases.

\section{Funding}

None.

\section{Conflict of interest}

None. 


\section{References}

1 Goodwin CR, Boone CE, Pendleton J, Elder BD, Wei Z, Hsu W, et al. Pneumocephalus leading to the diagnosis of cerebrospinal fluid leak and esophageal perforation after cervical spine surgery. J Clin Neurosci 2016;26:141-142

2 Sloan T. The incidence, volume, absorption, and timing of supratentorial pneumocephalus during posterior fossa neurosurgery conducted in the sitting position. J Neurosurg Anesthesiol 2010;22:59-66

3 Derner M, Drugová B, Horejší L, Skvára D, Druga R. Massive pneumorrhachis, pneumocephalus and pneumoopticus following thoracic trauma and avulsion of the brachial plexus: Case report and review of the literature. Prague Med Rep 2011;112:56-66

4 Jagia M, Kapoor MC, Panjiar P. Pneumocephalus after epidural analgesia: Should loss of resistance with air be blown out? J Anaesthesiol Clin Pharmacol 2016;32:272-273

5 Kim YD, Ham HD, Moon HS, Kim SH. Delayed pneumocephalus following fluoroscopy guided cervical interlaminar epidural steroid injection: A rare complication and anatomical considerations. J Korean Neurosurg Soc 2015;57:376-378
6 Akyüz O, Gökpinar D, Aydin E, Aydin S, Duymus M, Çigsar G, et al. Pneumocephalus and pneumorrhachis after spinal surgery. Pol J Radiol 2016;81:34-35

7 Karavelioglu E, Eser O, Haktanir A. Pneumocephalus and pneumorrhachis after spinal surgery: Case report and review of the literature. Neurol Med Chir (Tokyo) 2014;54:405-407

8 Yun JH, Kim YJ, Yoo DS, Ko JH. Diffuse pneumocephalus: A rare complication of spinal surgery. J Korean Neurosurg Soc 2010;48:288-290

9 Turgut M, Akyüz O. Symptomatic tension pneumocephalus: An unusual post-operative complication of posterior spinal surgery. J Clin Neurosci 2007;14:666-668

10 Pirris SM, Nottmeier EW. Symptomatic pneumocephalus associated with lumbar dural tear and reverse trendelenburg positioning: A case report and review of the literature. Case Rep Neurol Med 2013;2013:792168

11 Paiva WS, de Andrade AF, Figueiredo EG, Amorim RL, Prudente M, Teixeira MJ. Effects of hyperbaric oxygenation therapy on symptomatic pneumocephalus. Ther Clin Risk Manag 2014;10:769-773

12 Gore PA, Maan H, Chang S, Pitt AM, Spetzler RF, Nakaji P. Normobaric oxygen therapy strategies in the treatment of postcraniotomy pneumocephalus. J Neurosurg 2008;108:926-929 